\title{
TOKSISITAS AKUT FORMULASI INSEKTISIDA ENDOSULFAN, KLORPIRIFOS, DAN KLORFLUAZURON PADA TIGA JENIS IKAN AIR TAWAR DAN UDANG GALAH
}

\author{
Santosa Koesoemadinata*
}

\begin{abstract}
ABSTRAK
Salah satu upaya untuk mencegah pencemaran pestisida pada sumber daya dan lingkungan perikanan air tawar ialah dengan penggunaan bahan aktif pestisida secara selektif, yakni yang tidak berdaya racun tinggi pada ikan dan hewan akuatik lainnya. Penelitian tentang toksisitas akut tiga formulasi insektisida pertanian, endosulfan, klorpirifos, dan klorfluazuron telah dilakukan terhadap tiga jenis ikan air tawar, yakni ikan mas (Cyprinus carpio), ikan nila (Oreochromis niloticus), dan ikan lele (Clarias batrachus), serta terhadap udang galah (Macrobrachium rosenbergii). Uji toksisitas akut dilakukan dengan metode statik dan penggantian larutan uji (renewal toxicity test), untuk menentukan nilai LC50 (Median Lethal Concentration) pada waktu dedah 96 jam. Hasil penelitian menunjukkan bahwa tingkat toksisitas akut ketiga formulasi insektisida tersebut terhadap ikan dan udang adalah sebagai berikut : endosulfan > klorpirifos > klorfluazuron. Suseptibilitas (kerentanan) hewan uji terhadap keracunan endosulfan dan klorpirifos adalah: udang galah > ikan nila > ikan lele > ikan mas, sedang terhadap keracunan klorfluazuron adalah: ikan lele $>$ udang galah $>$ ikan nila $>$ ikan mas
\end{abstract}

ABSTRACT: Acute toxicity of the insecticide formulation of endosulphan, chlorpyrifos, and chlorfluazuron to three freshwater fish species and the freshwater giant prawn. By: Santosa Koesoemadinata

Heavy usage of agricultural insecticides produce potential detrimental effects on the fishery resources and aquatic environment. To minimize the problem of pollution brought by these chemicals, the use of selected low toxic pesticides should be encouraged. The acute toxicity of three insecticide formulations, i.e. endosulfan, chlorpyrifos, and chlorfluazuron to three freshwater fish species (common carp, nile tilapia, and java catfish) and freshwater giant prawn were evaluated in laboratory, using a renewal toxicity test system. The Median Lethal Concentration ( $L C 50)$ values of the insecticide formulations for 96 hours exposure period were recorded. Results of the tests indicated variations in the acute toxicity level of the insecticides to fish and prawn, as follows: endosulphan > chlorpyrifos > chlorfluazuron. The susceptibility of the test animals to endosulfan and to chlorpyrifos was in the following increasing order: giant prawn > nile tilapia > catfish > common carp, and to chlorfluazuron: catfish > giant prawn > nile tilapia > common carp.

KEYWORDS: insectisida, acute toxicity, freshwater, and giant prawn

\section{PENDAHULUAN}

Pemakaian pestisida di sektor pertanian, kehutanan dan kesehatan lingkungan masyarakat cenderung meningkat sejalan dengan meningkatnya pembangunan di sektor-sektor tersebut. Pestisida sebagai pembasmi hama yang efektif, perlu memiliki dua karakteristik utama, yakni toksisitas dan daya persistensi. Pestisida yang berspektrum luas dan toksik terhadap berbagai organisme bukan sasaran, masih banyak digunakan. Ditinjau dari segi kelestarian lingkungan, khususnya ekosistem akuatik perikanan, peningkatan pemakaian bahan-bahan beracun ini perlu dicermati secara khusus agar tidak menimbulkan dampak yang negatif. Pencemaran pestisida pada sumber daya dan lingkungan perikanan air tawar dapat mengakibatkan kematian ikan, penurunan produktivitas dan kualitas ikan sebagai sumber protein hewani. Menurut Sharom et al. (1980) dampak negatif pestisida terhadap kehidupan ikan dan biota akuatik lainnya ditentukan oleh toksisitas, daya persistensi, dan degradabilitas bahan racun tersebut. Suseptibilitas (kerentanan) jenis ikan dan udang maupun biota akuatik lainnya terhadap keracunan pestisida juga dapat bervariasi (Clark et al.,1985). Dengan demikian manifestasi dampak pencemaran pestisida di suatu ekosistem dapat berbeda.

Penelitian ini bertujuan untuk menentukan toksisitas akut tiga formulasi insektisida yakni endosulfan, klorpirifos, dan klorfluazuron terhadap tiga jenis ikan kultur air tawar yakni ikan mas (Cyprinus carpio), nila (Oreochromis niloticus), dan lele(Clarias batrachus), serta terhadap udang galah (Macrobrachium rosenbergii). Ketiga jenis ikan kultur

Peneliti pada Balai Penelitian Perikanan Tawar 
dan udang air tawar tersebut adalah komoditas perikanan air tawar yang bernilai ekonomis tinggi. Formulasi-formulasi insektisida yang diteliti khususnya endosulfan dan klorpirifos, banyak digunakan di sektor pertanian dan perkebunan.

\section{BAHAN DAN METODE}

\section{Bahan}

Sebagai bahan percobaan dipakai formulasi dagang insektisida dengan nama umum, kadar, dan nama kimia bahan aktif ( Tabel 1) (renewal test) yang dibakukan oleh OECD (1992). Untuk pengujian toksisitas pada ikan digunakan 24 bak kaca yang dilapisi stereofom dan serat kaca, berukuran $50 \times 30 \times 30 \mathrm{~cm}^{3}$ (px|xt). Bak-bak ini dilengkapi dengan pipa-pipa pelimpasan dari PVC untuk memudahkan penggantian larutan uji selama percobaan. Volume larutan uji $20 \mathrm{~L}$, yakni campuran atau dispersi insektisida yang homogen dalam air sumur pada kepekatan (konsentrasi) tertentu. Jumlah ikan uji 10 ekor per bak. Pengujian dilakukan dalam tiga ulangan. Selama percobaan larutan uji diberi aerasi dan kadar oksigen terlarut dijaga agar selalu

Tabel 1. Nama umum, kadar, dan nama kimia bahan aktif formulasi insektisida yang dipakai dalam percobaan Table 1. Common name, content, and chemical names of the active ingredient of insecticide formulations used in the experiment

\begin{tabular}{|c|c|c|}
\hline Nama umum (Common name) & Kadar (Content) & Nama kimia (Chemical name) \\
\hline Endosulfan (Endosulphan) & $350 \mathrm{~g} / \mathrm{L}$ & $\begin{array}{l}6,7,8,9,10,10 \text {-heksakloro-1,5,5a,6,9,9a-heksahidro- } \\
6,9 \text {-metano-2,4,3-benzodi-oksatipin-3-oksida }\end{array}$ \\
\hline Klorpirifos (Chlorpyirifos) & $200 \mathrm{~g} / \mathrm{L}$ & 0,0-dietilo-(3,5,6-trikloro-2-piridil) fosforotioat \\
\hline Klorfluazuron (Chlorfluazuron) & $50 \mathrm{~g} / \mathrm{L}$ & $\begin{array}{l}\text { N- [4-(3-chloro-5-trifluorometil-2-piridiloksi)-3,5- } \\
\text { diklorofenil]-N1-(2,6-difluorobenzoil) urea }\end{array}$ \\
\hline
\end{tabular}

Sebagai hewan uji dipakai benih ikan mas, ikan nila, ikan lele, dan tokolan udang galah, dengan bobot dan panjang baku (Tabel 2).

Tabel 2. Bobot dan panjang baku rata-rata ( \pm standar deviasi, SD) hewan uji $(\mathrm{N}=60)$

Table 2. Mean weight and mean standard length ( \pm standard deviation, SD) of test anima/s ( $N=60)$

\begin{tabular}{lcc}
\hline \multicolumn{1}{c}{ Hewan uji/Test animal } & $\begin{array}{c}\text { Bobot rata-rata }(\mathrm{g}) \pm \mathrm{SD} \\
\text { Mean weight }(\mathrm{g}) \pm \mathrm{SD}\end{array}$ & $\begin{array}{c}\text { Panjang baku rata-rata }(\mathrm{cm}) \pm \mathrm{SD} \\
\text { Mean standard length }(\mathrm{cm}) \pm S D\end{array}$ \\
\hline Ikan mas (Cyprinus carpio) & $1.4 \pm 0.2$ & $4.5 \pm 0.3$ \\
Ikan nila (Oreochromis niloticus) & $1.7 \pm 0.1$ & $3.8 \pm 0.3$ \\
Ikan lele (Clarias batrachus) & $0.6 \pm 0.5$ & $4.8 \pm 0.5$ \\
Udang galah (Macrobrachium rosenbergii) & $0.5 \pm 0.1$ & $4.9 \pm 0.3$ \\
\hline
\end{tabular}

Ikan uji diperoleh dari petani pembenih di Sukamandi, Subang, sedang tokolan udang galah berasal dari BBI Cisolok, Sukabumi. Sebelum digunakan untuk percobaan, hewan uji diadaptasikan di laboratorium selama 7-10 hari. Stok populasi hewan uji tidak digunakan untuk percobaan, bila kematian hewan uji selama masa adaptasi tersebut lebih dari $10 \%$, ada wabah penyakit atau jumlah individu yang cacat lebih dari 1\%. Selama masa adaptasi hewan uji diberi makan pakan komersial (3\%-5\% bobot badan/hari). Satu hari sebelum dipakai untuk percobaan, ikan uji dipuasakan.

\section{Metode}

Percobaan dilakukan dengan mengikuti metode uji toksisitas akut dengan sistem penggantian air di atas $60 \%$ saturasi. Larutan uji diganti setiap 48 jam sekali (dengan konsentrasi yang sama). Hal ini dilakukan untuk menjaga agar konsentrasi larutan di bak-bak pengujian relatif konstan. Penurunan konsentrasi uji dapat terjadi karena penguapan, adsorpsi pada dinding kaca bak uji dan penyerapan oleh tubuh ikan uji. Penggantian larutan uji juga penting dilakukan untuk membersihkan larutan uji dari kotoran hewan uji yang dapat menurunkan mutu air larutan tersebut (khususnya karena peningkatan kadar amonia)

Pengujian toksisitas pada udang galah dilakukan dalam bak-bak kaca berukuran $60 \times 40 \times 40 \mathrm{~cm}^{3}$ (pxlxt), dengan ketinggian air $10 \mathrm{~cm}$. Kondisi pengujian lainnya sama seperti pada pengujian dengan ikan. Pengujian toksisitas akut dilakukan dalam dua tahap, yakni tahap pendahuluan untuk menentukan konsentrasi insektisida yang mematikan 0\% hewan uji (ambang atas), dan konsentrasi yang mematikan 100\% hewan uji (ambang bawah), dalam waktu dedah 48 jam. Tahap 
Tabel 3. Konsentrasi uji pada pengujian toksisitas akut insektisida endosulfan, klorpirifos, dan klorfluazuron pada tiga jenis ikan air tawar dan udang galah

Table 3. Test concentrations used in the acute toxicity tests of the insecticide endosulphan, chlorpyrifos and chlorfluazuron to three freshwater fish species and freshwater giant prawn

\begin{tabular}{|c|c|c|c|c|c|c|}
\hline \multirow{3}{*}{$\begin{array}{l}\text { Insektisidallnsecticide } \\
\text { Jenis ikan/Fish species } \\
\text { Endosulfan/Endosulphan }\end{array}$} & \multicolumn{6}{|c|}{ Konsentrasi uji (mg/L)/ } \\
\hline & \multicolumn{6}{|c|}{ Test concentration ( $\mathrm{mg} / \mathrm{L})$} \\
\hline & & & & & & \\
\hline Ikan mas/Common carp & 0.01 & 0.0135 & 0.018 & 0.024 & 0.032 & \\
\hline Ikan nila/Nile tilapia & 0.0075 & 0.01 & 0.0135 & 0.018 & 0.024 & \\
\hline Ikan lele/Java catfish & 0.0135 & 0.0155 & 0.018 & 0.021 & 0.024 & \\
\hline Udang galah/Giant prawn & 0.0042 & 0.0056 & 0.0075 & 0.01 & 0.013 & 0.018 \\
\hline \multicolumn{7}{|l|}{ Klorpirifos/Chlorpyrifos } \\
\hline Ikan mas/Common carp & 1.8 & 2.4 & 3.2 & 4.2 & 5.6 & 7.5 \\
\hline Ikan nila/Nile tilapia & 0.1 & 0.135 & 0.18 & 0.24 & 0.32 & 0.42 \\
\hline Ikan lele/Java catfish & 0.75 & 1.00 & 1.8 & 2.4 & 3.2 & \\
\hline Udang galah/Giant prawn & 0.0075 & 0.01 & 0.0135 & 0/018 & 0.024 & \\
\hline \multicolumn{7}{|l|}{ Klorfluazuron/Chlorfluaz uron } \\
\hline Ikan mas/Common carp & 24 & 32 & 42 & 56 & 75 & \\
\hline Ikan nila/Nile tilapia & 18 & 24 & 32 & 42 & 56 & \\
\hline Ikan lele/Java catfish & 5.6 & 7.5 & 10 & 13.5 & 18 & 24 \\
\hline Udang galah/Giant prawn & 18 & 24 & 32 & 42 & 56 & \\
\hline
\end{tabular}

ini diteruskan dengan tahap lanjutan, dengan dilakukan pengujian terhadap 6 konsentrasi di antara ambang atas dan ambang bawah, yang ditentukan berdasarkan deret logaritmik, dan satu kontrol (tanpa pestisida). Konsentrasi-konsentrasi uji ketiga formulasi insektisida bagi ke empat hewan uji tertera pada Tabel 3. Tahap pengujian lanjutan dilakukan selama waktu dedah 96 jam. Pemeriksaan mortalitas hewan uji pada hari pertama percobaan dilakukan setiap jam, dan selanjutnya setiap 24 jam. Hewan uji yang mati segera diambil agar tidak mengotori larutan uji. Mortalitas hewan uji dicatat secara kumulatif pada waktu dedah 24, 48, 72, dan 96 jam, dan diolah secara statistik dengan analisis probit (Finney, 1971). Hasil percobaan dinyatakan dalam nilai LC50 (Median Lethal Concentration), yakni konsentrasi yang mematikan 50\% hewan uji pada kondisi dan waktu dedah tertentu, dengan nilai-nilai intervalnya pada Limit Kepercayaan 95\%. Konsentrasi-konsentrasi uji tidak diverifikasi secara analisis kimia dan nilai-nilai LC50 ini ditentukan berdasarkan konsentrasi nominal insektisida dalam bak-bak percobaan.

Karakteristik fisika dan kimia larutan uji selama percobaan harus memenuhi kriteria untuk pengujian toksisitas (APHA et al., 1984). Oleh karena itu selama pengujian dilakukan pemeriksaan beberapa parameter mutu air tertentu, yakni suhu, oksigen terlarut, $\mathrm{pH}, \mathrm{N}$-ammonia, kesadahan total, dan alkalinitas total

\section{HASIL DAN BAHASAN}

Hasil pengujian toksisitas akut ketiga formulasi insektisida terhadap ikan dan udang air tawar, tertera pada Tabel 4 sampai 6. Nilai-nilai LC50 pada tabel tersebut dinyatakan dalam $\mathrm{mg} / \mathrm{L}$ produk formulasi insektisida, tidak dalam bahan aktif. Hal ini dilakukan karena menurut Jarvinen \& Tannel (1982) campuran yang terdapat dalam produk komersial pestisida seperti pelarut, pengemulsi, dispersan, dan lain-lain, dapat mempengaruhi daya racun senyawa kimia tersebut. Pengaruh ini dapat bersifat sinergistik yakni memperkuat daya racun, ataupun antagonistik, yakni memperlunak daya racun pestisida terhadap ikan Oleh karena itu pengujian toksisitas pestisida dalam bentuk formulasi komersial dapat memberikan data yang lebih relevan tentang dampak pemakaiannya di lapangan.

Hasil pemeriksaan sifat fisika dan kimia larutan uji selama percobaan tertera pada Tabel 7. Data karakteristik fisika dan kimia larutan uji tercatat dalam batas-batas normal dan tidak menunjukkan fluktuasi yang dapat mempengaruhi hasil pengujian. Kesadahan larutan uji tercatat rendah ( $<50 \mathrm{mg} \mathrm{CaCO} / \mathrm{L})$, akan tetapi masih dalam batas wajar untuk pengujian toksisitas ikan, yang dapat dilakukan pada kesadahan air tinggi maupun rendah (OECD, 1992)

Hasil percobaan menunjukkan bahwa tingkat daya racun formulasi insektisida terhadap ikan dan udang 
Tabel 4. Toksisitas akut formulasi insektisida endosulfan $(350 \mathrm{~g} / \mathrm{L})$ pada ikan dan udang air tawar

Table 4. Acute toxicity of the insecticide formulation of endosuphan $(350 \mathrm{~g} / \mathrm{L})$ to freshwater fish and prawn

\begin{tabular}{|c|c|c|}
\hline $\begin{array}{l}\text { Waktu dedah (jam) } \\
\text { Exposure period (hours) }\end{array}$ & LC50 (mg/L) LC50 (mg/L) & $\begin{array}{c}\text { Persamaan garis probit } \\
\text { Estimated probit line }\end{array}$ \\
\hline \multicolumn{3}{|l|}{ Tkan mas/Cyprinus carpio } \\
\hline 24 & $0,0182(0,0175-0,0188)$ & $y=12,41 x-10,64$ \\
\hline 48 & $0,015 \quad(0,0142-0,0158)$ & $y=9,58 x-6,27$ \\
\hline 72 & $0,0139(0,0131-0,0148)$ & $y=10,84 x-7,41$ \\
\hline 96 & $0,0129(0,0122-0,0137)$ & $y=11,66 x-7,97$ \\
\hline \multicolumn{3}{|l|}{ Ikan nila/Oreochromis niloticus } \\
\hline 24 & $0,0132(0,0127-0,0137)$ & $y=11,95 x-20,36$ \\
\hline 48 & $0,0112(0,0106-0,0118)$ & $y=8,75 x-12,95$ \\
\hline 72 & $0,0102(0,0095-0,0011)$ & $y=8,56 x-12,23$ \\
\hline 96 & $0,0095(0,0089-0,0102)$ & $y=9,55 x-13,92$ \\
\hline \multicolumn{3}{|l|}{ Ikan lele/Clarias batrachus } \\
\hline 24 & $0,0205(0,0198-0,0211)$ & $y=21,07 x-22,64$ \\
\hline 48 & $0,0183(0,018-0,0186)$ & $y=25,36 x-26,92$ \\
\hline 72 & $0,0181(0,0178-0,0184)$ & $y=25,66 x-27,29$ \\
\hline 96 & $0,0178(0,0175-0,0181)$ & $y=26,47 x-28,11$ \\
\hline \multicolumn{3}{|c|}{ Udang galah/Macrobrachium rosenbergii } \\
\hline 24 & $0,0082(0,0078-0,0085)$ & $y=9,39 x-12,99$ \\
\hline 48 & $0,0066(0,0064-0,0068)$ & $y=11,06 x-15,17$ \\
\hline 72 & $0,0064(0,0062-0,0066)$ & $y=14,22 x-20,74$ \\
\hline 96 & $0,0064(0,0062-0,0066)$ & $y=14,22 x-20,71$ \\
\hline
\end{tabular}

*) LC50 dengan nilai-nilai intervalnya pada limit kepercayaan 95\%/LC50 and their $95 \%$ - confidence limit intervals

Tabel 5. Toksisitas akut formulasi insektisida klorpirifos ( $200 \mathrm{~g} / \mathrm{L}$ ) pada ikan dan udang air tawar

Table 5. Acute toxicity of the insecticide formulation of ethyl chlorpyrifos ( $200 \mathrm{~g} / \mathrm{L})$ on freshwater fish and prawn

\begin{tabular}{|c|c|c|}
\hline $\begin{array}{c}\text { Waktu dedah (jam) } \\
\text { Exposure period (hours) }\end{array}$ & LC50 (mg/L) LC50 (mg/L) & $\begin{array}{l}\text { Persamaan garis probit } \\
\text { Estimated probit line }\end{array}$ \\
\hline \multicolumn{3}{|l|}{ Ikan mas/Cyprinus carpio } \\
\hline 24 & $4,289(4,124-4,46)$ & $y=10,59 x-12,28$ \\
\hline 48 & $3,814(3,656-3,97)$ & $y=9,73 x-10,38$ \\
\hline 72 & $3,731(3,578-3,89)$ & $9,83 x-10,45$ \\
\hline 96 & $3,617(3,469-3,77)$ & $9,91 x-10,45$ \\
\hline \multicolumn{3}{|l|}{ Ikan nila/Oreochromis niloticus } \\
\hline 24 & $0,217(0,208-0,227)$ & $y=9,54 x-7,77$ \\
\hline 48 & $0,201(0,192-0,209)$ & $y=9,77 x-7,73$ \\
\hline 72 & $0,157(0,149-0,166)$ & $y=8,47 x-5,16$ \\
\hline 96 & $0,151(0,141-0,162)$ & $y=8,29 x-4,8$ \\
\hline \multicolumn{3}{|l|}{ Ikan lele/Clarias batrachus } \\
\hline 24 & $1,416(1,357-1,478)$ & $y=9,68 x-15,83$ \\
\hline 48 & $1,332(1,285-1,38)$ & $y=10,75 x-17,85$ \\
\hline 72 & $1,111(1,048-1,177)$ & $y=8,51 x-12,4$ \\
\hline 96 & $1,097(1,034-1,164)$ & $8,42 x-12,18$ \\
\hline \multicolumn{3}{|c|}{ Udang galah/Macrobrachium rosenbergii } \\
\hline 24 & $0,0104(0,0097-0,0113)$ & $y=7,32 x-9,8$ \\
\hline 48 & $0,0102(0,0094-0,0111)$ & $y=7,21 x-9,5$ \\
\hline 72 & $0,0101(0,0094-0,011)$ & $y=7,53 x-10,07$ \\
\hline 96 & $0,0101(0,0094-0,011)$ & $y=7,53 x-10,07$ \\
\hline
\end{tabular}

*) LC50 dengan nilai-nilai intervalnya pada limit kepercayaan 95\%/LC50 and their $95 \%$ - confidence limit intervals 
Tabel 6. Toksisitas akut formulasi insektisida klorfluazuron ( $500 \mathrm{~g} / \mathrm{L}$ ) pada ikan dan udang air tawar Table 6. Acute toxicity of the insecticide formulation of chlorfluazuron ( $500 \mathrm{~g} / \mathrm{L})$ to freshwater fish and prawn

\begin{tabular}{ccc}
\hline $\begin{array}{c}\text { Waktu dedah (jam) } \\
\text { Exposure period (hours) }\end{array}$ & LC50 (mg/L) LC50 (mg/L) & $\begin{array}{c}\text { Persamaan ga ris probit } \\
\text { Estimated probit line }\end{array}$ \\
\hline Ikan mas/Cyprinus carpio & & \\
24 & $48,524(46,989-50,109)$ & $y=14,03 x-18,65$ \\
48 & $47,162(45,75-48,619)$ & $y=14,38 x-19,06$ \\
72 & $46,325(44,971-47,721)$ & $y=14,63 x-19,37$ \\
96 & $41,559(40,178-42,989)$ & $y=13,03 x-16,09$ \\
Ikan nila/Oreochromis niloticus & & \\
24 & $37,233(35,994-38,515)$ & $y=13,85 x-16,75$ \\
48 & $34,063(32,891-35,278)$ & $y=12,31 x-13,87$ \\
72 & $33,301(32,163-34,48)$ & $y=12,96 x-14,73$ \\
96 & $33,059(31,938-34,22)$ & $y=13,04 x-14,82$ \\
Ikan lele/Clarias batrachus & & \\
24 & $18,345(16,931-19,877)$ & $y=8.29 x-13,77$ \\
48 & $15,67(14,568-16,855)$ & $y=$ \\
72 & $13,635(13,099-14,192)$ & $y=10,52 x-17,45$ \\
96 & $13,312(12,807-13,838)$ & $y=10,67 x-17,68$
\end{tabular}

bervariasi dan tergantung pada kandungan jenis dan kadar bahan aktif formulasi tersebut, serta pada jenis ikan. Hasil percobaan juga menunjukkan adanya suseptibilitas hewan uji terhadap racun insektisida yang berbeda. Udang galah lebih rentan terhadap keracunan endosulfan dan klorpirifos dibandingkan terhadap ikan mas, ikan nila, dan ikan lele, akan tetapi lebih tahan terhadap keracunan klorfluazuron dibandingkan dengan ikan lele

Berdasarkan toksisitas akut bahan aktifnya pada ikan, Bathe et al. (1974) mengklasifikasikan daya racun pestisida dalam empat peringkat sebagai sangat tinggi (LC50-48 jam: < 0,5 mg/L), tinggi (LC5048jam: 0,5-5 mg/L), sedang (LC50-48jam: $5-50$ mg/ L), dan rendah (LC50-48jam: > $50 \mathrm{mg} / \mathrm{L})$. Berdasarkan peringkat daya racun tersebut, maka endosulfan dan klorpirifos tergolong pestisida yang berdaya racun sangat tinggi pada ikan. Insektisida klorfluazuron tergolong pestisida yang berdaya racun sedang pada ikan mas dan ikan nila, akan tetapi berdaya racun tinggi pada ikan lele

Hasil pengujian di atas sesuai dengan pendapat beberapa peneliti yang menyatakan bahwa senyawa endosulfan, 6, 7, 8,9,10,10-heksakloro-1, 5, 5a, 6, 9,9aheksahi-dro-6, 9-metano-2, 4, 3-benzodioksatipin-3oksida), berdaya racun sangat tinggi pada ikan dan biota air lainnya (Macek et al., 1972; Schoettger, 1970; Schimmel et al.,1977; dan Singh \& Narain,1982). Tingginya daya racun disebabkan antara lain karena proses metabolisme senyawa ini dalam tubuh ikan hanya mampu menguraikannya menjadi endosulfan sulfat yang masih toksik pada ikan (Anonim,1980 dan Rao et.al,1981). Senyawa siklodien ini bersifat toksik pada jenis-jenis ikan air tawar maupun jenis-jenis ikan air payau di Amerika Serikat, masing-masing pada konsentrasi $0,2-8,1 \mathrm{mg} / \mathrm{L}$ dan $0,3-2,9 \mathrm{mg} / \mathrm{L}$ (Schoettger, 1970 dan Anonim,1980). Nilai LC50-96 jam endosulfan untuk ketiga jenis ikan air tawar dalam percobaan ini tercatat antara 3,2 dan 6,2 mg/L (bahan aktif), dan berada dalam angka kisaran tersebut di atas. Menurut Singh \& Narain (1982), toksisitas endosulfan pada ikan lele air tawar (Heteropneustes fossilis) dipengaruhi oleh musim dan ukuran ikan yang diuji. Pada musim panas daya tahan ikan terhadap insektisida ini cenderung menurun. Hal ini mungkin juga berlaku terhadap pestisida dan bahan racun lainnya. Residu endosulfan berpengaruh buruk pada lingkungan air payau atau estuarin. Hasil penelitian Schimmel et al. (1977) menunjukkan bahwa nilai LC50-96 jam insektisida ini pada beberapa jenis udang estuarin berkisar antara 0,04 mg/L dan 1,3 mg/L. Residu endosulfan di estuarin pada tingkat $0,01 \mathrm{mg} / \mathrm{L}$ dapat mematikan udang Penaeus duorarum. 
Tabel 7. Karakteristik fisika dan kimia larutan uji selama percobaan toksisitas akut tiga formulasi insektisida terhadap ikan dan udang air tawar

Table 7. Physical and chemical characteristics of dilution water used in the acute toxicity tests of three insecticide formulations on freshwater fish and prawn

\begin{tabular}{|c|c|c|c|c|c|c|}
\hline \multirow[b]{2}{*}{ Parameter/Parameter } & \multicolumn{2}{|c|}{ Percobaan (Test) } & \multicolumn{2}{|c|}{ Percobaan (Test) II } & \multicolumn{2}{|c|}{ Percobaan (Test) 11} \\
\hline & $\begin{array}{l}\text { Rata }^{2} \\
\text { Mean }\end{array}$ & $\begin{array}{l}\text { Kisaran } \\
\text { Range }\end{array}$ & $\begin{array}{l}\text { Rata }^{2} \\
\text { Mean }\end{array}$ & $\begin{array}{l}\text { Kisaran } \\
\text { Range }\end{array}$ & $\begin{array}{l}\text { Rata }^{2} \\
\text { Mean }\end{array}$ & $\begin{array}{l}\text { Kisaran } \\
\text { Range }\end{array}$ \\
\hline $\begin{array}{l}\text { Suhu }\left({ }^{\circ} \mathrm{C}\right) \text { Temperature }\left({ }^{\circ} \mathrm{C}\right) \\
\mathrm{pH} \\
\text { Oksigen terlarut }(\mathrm{mg} / \mathrm{L})\end{array}$ & $\begin{array}{c}29,23 \\
8\end{array}$ & $\begin{array}{l}29,1-29,4 \\
8-8\end{array}$ & $\begin{array}{c}28,4 \\
8\end{array}$ & $\begin{array}{l}\text { 28,0-28,9 } \\
\text { 8-Aug }\end{array}$ & $\begin{array}{c}27,56 \\
8\end{array}$ & $\begin{array}{l}27,5-27,6 \\
8 \text {-Aug }\end{array}$ \\
\hline $\begin{array}{l}\text { Dissolved oxygen (mg/L) } \\
\mathrm{CO}_{2} \text { bebas }(\mathrm{mg} / \mathrm{L}) \text { Free } \mathrm{CO}_{2}\end{array}$ & 6,6 & $6,4-7,2$ & 6,76 & $6,4-7,4$ & 6,64 & $6,4-7,2$ \\
\hline$(\mathrm{mg} / \mathrm{L})$ & 0 & $0-0$ & 0 & 0 & 0 & $0-0$ \\
\hline $\begin{array}{l}\mathrm{N} \text {-amonia }(\mathrm{mg} / \mathrm{L}) \mathrm{N}-\mathrm{NH}_{3}(\mathrm{mg} / \mathrm{L}) \\
\text { Alkalinitas total }(\mathrm{mg}\end{array}$ & 0,056 & $0,044-0,067$ & 0,044 & $0,037-0,052$ & 0,067 & $0,055-0,085$ \\
\hline $\begin{array}{l}\left.\mathrm{CaCO}_{3} / \mathrm{L}\right) \text { Total alkalinity (mg } \\
\left.\mathrm{CaCO}_{3} / \mathrm{L}\right)\end{array}$ & 115,2 & $114,8-116,9$ & 121,8 & $119,9-129,2$ & 123,9 & $119,9-129,9$ \\
\hline $\begin{array}{l}\text { Kesadahan total ( } \mathrm{mg} \mathrm{CaCO} / \mathrm{L} \text { ) } \\
\text { Total hardness ( } \mathrm{mg} \mathrm{CaCO}_{3} / \mathrm{L} \text { ) }\end{array}$ & 20,4 & $20,4-20,4$ & 36,7 & $36,7-36,7$ & 28,4 & $28,0-30,0$ \\
\hline
\end{tabular}

Percobaan 1/Test 1 - endosulfan/endosulphan

Percobaan 2/Test 2 - klorpirifos/chlorpyrifos

Percobaan 3/Test 3 - klorfluaz uron/chlorfluazuron

Biokonsentrasi residu (BCF = Biological Concentration Factor) endosulfan dalam tubuh ikan juga sangat tinggi, yakni 2.400 kali residu dalam air.

Senyawa bahan aktif klorpirifos, 0,0-dietil 0-(3,5,6trikloro-2-piridil) fosforotioat, dapat mematikan ikan pada tingkat konsentrasi yang sangat rendah (Anonim,1980 dan Ananda et al.,1981). Menurut Johnson \& Finley (1980) LC50-96jam insektisida klorpirifos bagi jenis-jenis ikan air tawar di Amerika Serikat berkisar antara 2,4 mg/L dan $280 \mathrm{mg} / \mathrm{L}$. Barron \& Woodburn (1995) menyatakan bahwa berdasarkan data LC50, insektisida ini berdaya racun sangat akut terhadap ikan air tawar maupun ikan air asin pada kisaran konsentrasi 0,5 dan 1.000 mg/L. Angka-angka kisaran ini sesuai dengan hasil pengujian terhadap ikan nila, ikan lele maupun ikan mas (masing-masing 52 $\mathrm{mg} / \mathrm{L}, 219 \mathrm{mg} / \mathrm{L}$, dan $723 \mathrm{mg} / \mathrm{L}$, bila dikalkulasikan sebagai bahan aktif). Menurut El-Refai et al. (1976), LC50-48 jam formulasi klorpirifos untuk ikan nila adalah 114 (84-156) mg/L dan LC50-48 jam untuk ikan mas adalah 280 (236-332) mg/L. Hasil penelitian Hegazi (1989) menunjukkan bahwa LC50-96jam formulasi klorpirifos untuk ikan lele (Clarias lazera) dengan bobot individu rata-rata $24 \mathrm{~g}$, adalah $5.350 \mathrm{mg} / \mathrm{L}$. Angka-angka LC50 tersebut tidak jauh berbeda dengan angka-angka LC50 (dalam bahan formulasi) yang diperoleh dari hasilhasil pengujian toksisitas dalam tulisan ini.

Data hasil pengujian toksisitas akut klorpirifos terhadap ikan tampaknya secara predominan ditentukan oleh jenis ikan yang diuji. Akan tetapi perbedaan hasil percobaan toksisitas akut dapat disebabkan oleh banyak faktor, di samping jenis ikan (Macek \& Allister, 1970), ukuran atau stadia ikan (Bull \& Mclnerny,1974 dan Hashimoto et al., 1981). Faktorfaktor tersebut antara lain kualitas air (Cairns et al., 1975; Inglis \& Davis, 1972; Johnson \& Finley, 1980; dan Weber,1972), bahan formulasi pestisida yang digunakan dalam percobaan (Jarvinen \& Tanner, 1982 dan Priyamvadadewi et al., 1981) dan sistem pengujian yang digunakan (Borthwick et al.,1985 dan Mayer,1987). Toksisitas akut endosulfan tercatat lebih rendah pada pengujian dengan sistem statis (static test) dibandingkan dengan pada sistem mengalir (flowthrough test) (Anonim, 1980). Jarvinen et al. (1983) melaporkan hal yang sama pada pengujian dengan klorpirifos. Menurut para peneliti ini, rasio antara hasil uji statis/hasil uji sistem mengalir adalah < 2, yang kemungkinan disebabkan adanya disipasi klorpirifos pada sistem statis (Racke, 1993). Faktor lainnya yang dapat mempengaruhi hasil pengujian dalam sistem statis ialah menurunnya kadar oksigen terlarut yang disebabkan adanya ikan uji yang mati. Sebagai contoh, bila pada suhu $25^{\circ} \mathrm{C}$ dalam akuarium dengan kadar oksigen hampir jenuh terdapat 2 ekor ikan hidup dan 3 ekor ikan mati, maka dalam waktu semalam kadar tersebut akan menurun sampai kurang dari 1 mg/L (Shreck \& Brouha,1975). Masalah lain pada sistem statis ialah konsentrasi bahan uji dalam wadah pengujian yang akan menurun sejalan dengan waktu dedah. Perbedaan antara konsentrasi nominal dan konsentrasi aktual dalam wadah pengujian dapat 
berkisar antara 30\% sampai 45\% (Schimmel et al.,1977). Hal ini dapat menyebabkan rendahnya akurasi dan reprodusibilitas hasil pengujian toksisitas akut pada sistem tersebut.

Suhu air juga merupakan faktor yang mempengaruhi hasil pengujian toksisitas pestisida pada ikan. Cope (1965) melaporkan bahwa pada ikan salmon nilai LC50 akan berkurang sampai 50\% setiap peningkatan suhu $10^{\circ} \mathrm{C}$. Pada umumnya peningkatan suhu mengakibatkan peningkatan toksisitas bagi biota akuatik (Mayer \& Ellersieck,1986).

Formulasi dagang klorpirifos di kolam pada dosis yang efektif untuk pemberantasan nyamuk masih dapat menyebabkkan kematian ikan (Macek et al., 1972 dan Hurlbert et al.,1970). Menurut Smith et al. (1966), formulasi klorpirifos dapat terabsorpsi dengan cepat oleh air dan tanaman serta partikel tanah, akan tetapi proses metabolisme senyawa ini sangat lambat. Sebaliknya proses absorpsi senyawa ini oleh tubuh ikan agak lambat, akan tetapi proses penguraiannya terjadi dengan cepat. Baron \& Woodburn (1995) menyatakan bahwa klorpirifos dalam lingkungan terestrial maupun akuatik dapat terdegradasi melalui proses biotik dan abiotik. Proses degradasi ini terutama terjadi karena pemisahan ikatan ester fosforotiat yang membentuk 3,5,6-trikloro-2-piridinol (TCP). TCP ini dalam lingkungan terdegradasi melalui proses fotolisis (Dilling et al., 1984) dan mikrobial (Bidlack, 1976). Kedua proses tersebut menghasilkan waktu paruh klorpirifos yang relatif pendek, yakni 4 menit dalam air dan 73 hari dalam tanah.

Sekitar 30 tahun yang lalu, FAO telah mengklasifikasikan endosulfan dan insektisida organoklor lainnya seperti endrin, DDT, lindan, dan dieldrin, sebagai pestisida Golongan A, yakni senyawa kimia dengan toksisitas pada biota air $<5$ $\mathrm{mg} / \mathrm{L}$. Tingkat residu senyawa-senyawa ini yang aman bagi lingkungan akuatik $£ 50 \mathrm{hg} / \mathrm{L}$. Kadar residu yang aman ini sangat rendah sehingga senyawa-senyawa kimia tersebut tidak dapat diaplikasikan pada atau dekat suatu perairan tanpa membahayakan kelestarian sumber daya akuatik di perairan tersebut. Toksisitas akut (TLm-48jam) bahan aktif endosulfan pada ikan menurut kriteria ini adalah $0,2 \mathrm{mg} / \mathrm{L}$ (FAO, 1969).

Berdasarkan evaluasi FAO disebutkan di atas klorpirifos dikatagorikan sebagai pestisida Golongan $B$, yaitu senyawa kimia dengan toksisitas akut $<1$ $\mathrm{mg} / \mathrm{L}$. Tingkat residu yang diperbolehkan di lingkungan akuatik < $10 \mathrm{mg} / \mathrm{L}$. Toksisitas akut (TLm-48 jam) klorpirifos bagi ikan adalah $3,0 \mathrm{mg} / \mathrm{L}$. Evaluasi toksikologi akuatik yang dilaksanakan oleh FAO tersebut sampai kini belum diperbaharui dan secara umum masih dapat dipakai sebagai acuan untuk pelestarian perairan perikanan dari bahaya pencemaran pestisida

Klorfluazuron adalah pengatur tumbuh (growth regulator) bagi serangga yang digunakan untuk penanggulangan hama di tanaman hortikultura. Senyawa ini bekerja sebagai penghambat pembentukan lapisan kitin (chitin inhibitor) yang sangat aktif. Klorfluazuron tergolong senyawa urea (trifluorometil) dengan nama kimia N- [4-(3-chloro-5-trifluorometil-2-piridiloksi)-3,5diklorofenil]-N1-(2,6-difluorobenzoil) urea. Hasil pengujian menunjukkan bahwa insektisida ini berdaya racun sedang pada ikan mas, ikan nila, ikan lele maupun pada udang galah. LC50-48jam insektisida ini untuk ikan mas adalah 47,16 mg/L. Data LC5048jam untuk ikan mas (carp) yang diperoleh dari perusahaannya di Jepang adalah $>300 \mathrm{mg} / \mathrm{L}$. Perbedaan ini kemungkinan disebabkan karena kondisi percobaan dan jenis ikan percobaan yang berbeda.

Informasi tentang toksikologi akuatik senyawa bahan aktif ini, seperti umumnya senyawa-senyawa bahan aktif pestisida baru lainnya, belum banyak diperoleh

\section{KESIMPULAN}

- Formulasi insektisida endosulfan dan klorpirifos tergolong pestisida yang berdaya racun sangat tinggi pada ikan dan udang.

- Tingkat daya racun akut tiga formulasi insektisida yang diuji terhadap ikan dan udang air tawar adalah sebagai berikut : endosulfan > klorpirifos > klorfluazuron.

- Suseptibilitas (kerentanan) jenis-jenis ikan dan udang terhadap keracunan tiga formulasi insektisida berbeda, dan pada umumnya udang galah lebih rentan terhadap keracunan insektisida dibandingkan dengan ikan.

- Data base toksikologi akuatik formulasi-formulasi pestisida dengan bahan aktif baru yang digunakan di negara ini perlu diperoleh, untuk digunakan sebagai acuan dalam kebijaksanaannya pestisida yang ramah lingkungan, dan dalam penentuan baku perairan untuk perikanan.

\section{DAFTAR PUSTAKA}

Ananda S, P. D, D. Mohana Rao, dan A. S. Murty. 1981. Toxicity of endosulfan to the freshwater fish Cirrhinus mrigal. Bull. Environ. Contam. Toxicol. 27:850-852

Anoymus. 1980. Ambient Water Quality Criteria for Endosulfan. EPA 440/5/80046. Office of Water Regulation and Standard Criteria Division. EPA. Washington, $14 \mathrm{pp}$

APHA, AWWA dan WPCF.1984 i. APHA, Washington D.C., $16^{\text {th }}$ edition, p.843-869 
Barron, M. G dan K. B. Woodburn. 1995. Ecotoxicology of chlorpyrifos. Reviews of Environmental Contamination and Toxicology.Vol.144. 1995. Springer-Verlag New York, Inc. 93 pp.

Bathe, R, K. Sachsee, L. Ullman, W. D.Hormann, F. Zak, dan R. Hess. 1974. The evaluation of fish toxicity in the laboratory. Excepta Medica XVI: 113-124.

Bidlack, H. D. 1976. Degradation of 14C-labeled 3,5,6trochloro-2-pyridinol in 15 selected agricultural soils. Report GH-C 953 Dow Elanco, Indianapolis. 11 pp.

Bull, C. J, dan J. E. Mclnerny. 1974. Behaviour of juvenile coho salmon (Onchorhynchus kisutch) to sumithion (fenitrothion), an organophosphorous insecticide. J.Fish.Res.Board Can. 31:1867-1891.

Cairns, Jr. J, A. G. Heath, dan B. C. Parker. 1975. The effects of temperature upon the toxicity of chemical substances on aquatic life. J. Test. Evaluation, 6(2):8190

Clark, Jr, J. M. Patrick, D. P. Middaugh, dan J. C. Moore. 1985. Relative sensitivities of six estuarine fishes to carbophenothion, chlorpyrifos and fenvalerate. Ecotoxicol. Environ. Safe. 10: 382-390.

Cope,O.B.1965. Sport Fishery Investigation. Cirr.Fish Wildlife Service Washington, 226:51-63

Dilling, W. L, L. C. Lickly, T. D. Lickly, P. C. Murphy, dan R. L. McKellar. 1984. Organo photochemistry 19. Quantum yield for 0,0-diethyl 0-(3,5,6-trichloro-2 pyridyl) phosphorothioate (chlorpyrifos) and 3,5,6trichlor-opyridinol in aqueous solutions and their environmental photo trans-formation rates. Environ. Sci. Technol. 18:540-543.

El-Refai A, F. D. Fouad, M. F. Abdel-Latief, dan A. K. E. Imam. 1976. Toxicity of three insecticides to two species of fish. Int. Pest Control. 18: 4-8.

Finney, D. J. 1971. Probit Analysis. $3^{\text {rd }}$ edition. Cambridge at the University Press. 1971. 333 pp.

Hurlbert, G. W. M. S. Mulla, J. O. Keith, W. E. Westlake, dan Dusch, M. E. 1970. Biological effects and persistence of dursban in freshwater ponds. J. Econ.Entomol. 63:43-47

Hashimoto, Y, E. Okubo, T. Iyo, M. Yamaguchi, dan S. Tanaka. 1981. Changes in susceptibility of carp to several pesticides with growth. J. Pesticides Sci. 7:457-461

Hegazi, M. A. M. 1989. Brain acetlcholinesterase inhibition in juvenile Clarias lazare induced by chronic dursban intoxication. Delta J. Sci. 13:455-468.

Inglis, A dan E. L. Davis. 1972. Effects of Water Hardness on the Toxicity of Several Organic and Inorganic Herbicides to Fish. US Fish and Wildlife Service, Department of Interior, Washington, DC. $12 \mathrm{pp}$.

Jarvinen, A. W dan D. K. Tannel. 1982. Toxicity of selected controlled release and corresponding unformulated technical grade pesticides to the fathead minnows, Pimephales promelas. Environ. Pollut. Ser. A Ecol. Biol. 27:179-195.
Johnson, D. W dan M. T. Finley. 1980. Handbook of acute toxicity of chemicals to fish and aquatic invertebrates. US Dept. of the Interior Fish and Wildlife. Sec. Resource Publ.137 pp

Macek, K. J. dan W A. McAllister. 1970. Insecticide susceptibility of some common fish family. Trans. Am. Fish. Soc. 98(1):20-27.

Macek, K. J, D. F. Walsh, J. W. Hogan, and D. D. Holz. 1972. Toxicity of the insecti-cide durban to fish and aquatic invertebreates in ponds. Trans. Am. Fish. Soc. 101:420-424.

Mayer, F. L dan M. R. Ellersieck. 1986. Manual of Acute Toxicity: Interpretation and Data Base of 410 Chemicals and 66 Species of Freshwater Animals. Resource Publ 160. US Department of Interior, Washington DC.72 pp.

OECD. 1992. OECD Guide Lines for Testing of Chemicals No. 203. Fish, Acute Toxicity Test. Adopted 17.07.92. 4 pp.

Priyamvadadewi, A, D. M. R. Rao, K. S. Tilak, dan A. S. Murty. 1981. Relative toxicity of the technical grade material, isomer and formulations of endosulfan to the fish Channa punctata. Bull. Environ. Contam. Toxicol. 27:239-242

Racke, K. D. 1993. Environmental fate of chlorpirifos. Rev. Environ Contam Toxicol. 131:1-154.

Rao, D. M. R, A. P. Devi, dan A. S. Murty. 1981. Toxicity and metobolism of endo-sulfan and its effects on oxygen consumption and total nitrogen excretion of the fish Macronagthus aculentum. Pestic. Biochem. Physiol., 15:282-284

Schimmel, S. C, J. M. Patrick, Jr. dan A. J. Wilson, Jr. 1977. Acute toxicity to and biocon-centration of endosulfan by estuarine animals. In F.L.Mayerdan J. L. Hamelink Eds. "Aquatic Toxicology and Hazard Evaluation" American Society for Testing and Materials, 1977. p:241-253

Schoettger, R. A. 1970. Aquatic toxicology of thiodan. Investigation of Fish Control No. 35. US Dept. of Interior Fish and Wildlife Service, Bureau of Sport Fisheries and Wildlife, $31 \mathrm{pp}$

Singh, B. D dan A. S. Narain.1982. Acute toxicity of thiodan to catfish (Heterop-neustes fossilis). Bull. Environ. Contam. Toxicol. 28:122-127.

Smith, G. N, B. S. Watson, dan F. S. Foscher. 1966. The metabolism of $\left[{ }^{14} \mathrm{C}\right]$ 0,0-Diethyl 0-(3,5,6-trichloro-2pyridyl)phosphorothioate (dursban) in fish. J. Econom. Entomol. 59: 1464-1475

Shreck, C.B dan P.Brouha. 1975. Dissolved oxygen dipletion in static bioassay systems. Bull. Environ. Contam. Toxicol. 14: 149-153.

Weber, J. B. 1972. Interaction of organic pesticides with particulate matter in aquatic and soil system. In: Faust,S.D (Ed.). Fate of Organic Pesticides in the Aquatic Environment. Advances in Chemistry Series 111. Washington DC.American Chemistry Scoiety. p.55-64 